\title{
Achieving PCMH Status May Not Be Meaningful for Small Practices
}

\author{
Kelley K. Glancey, MD, James G. Kennedy, MD, MBA \\ Byers Peak Family Medicine, Winter Park, Colorado \\ Ann Fam Med 2016;14:4-5. doi: 10.1370/afm.1887.
}

$\mathrm{O}$ ur practice is a small, rural, 10 -year-old practice in the mountains of Colorado. We started our idealized micro practice (a practice with no nonprofessional employees) using the tenets set out by the Institute of Medicine report that has become the basis of the patient-centered primary care (PCMH) movement. ${ }^{1}$ In this issue of Annals of Family Medicine, Liaw et al outlined the percentage of small family medicine practices and the characteristics of these practices. ${ }^{2}$ The authors discuss how small family medicine practices can participate in new models of reimbursement without consolidation with other practices. Although there is a huge rush to quality payment, our experience supports the idea that this may not make sense for small rural practices.

We are very interested in ongoing quality improvement. Our practice's low overhead model allows for longer appointments, time for chronic disease management, sameday open-access scheduling, and patientcentered care. We have successfully attested for meaningful use of certified electronic health records (EHRs) every year and should qualify for stage 3 this year. We are also a 3rd-year Comprehensive Primary Care (CPCI) practice. Although the PCMH movement has resulted in some improvement in cost control for organizations and insurers, there is very little evidence for any improvement for individual practices. In fact, a review of the Patient-Centered Primary Care Collaborative's (PCPCC) 2014 report shows only modest improvement in cost or quality, and no overwhelming reception from patient or providers. Less than $50 \%$ of

Conflicts of interest: authors report none.

\section{CORRESPONDING AUTHOR}

James G. Kennedy

Byers Peak Family Medicine LLC

78878 Us Hwy

Winter Park, CO 80482

drk@byerspeakfm.com patients and $30 \%$ of providers report satisfaction with $\mathrm{PCMH}$, likely due to the increases in cost and amount of work with little to no increase in payment.

$\mathrm{CPCI}$ is one of the payment models recommended for the future payment under the looming Medicare Access and CHIP Reauthorization Act of 2015 (MACRA) that replaced sustainable growth rate (SGR). $\mathrm{CPCI}$ is based on a blended model of fee-for-service and care-coordination fees. For the first 2 years, this model did allow us to improve and complete our PCMH model. We created a full patient portal and patient advisory council, and built our EHR to deliver the various payment reports. The work necessary to create the reports and modify our EHR was difficult, and distracted at least 1 provider from patient care. Now in our 3rd year, the chronic disease management payment has been adjusted to a shared-risk model. The risk is based primarily on cost-saving targets for emergency department (ED) visits, hospitalizations, and hospital readmissions. At this point we know we will receive little shared savings from Anthem and it remains to be seen whether we will from other insurers. Because payments have decreased, many practices have opted out rather than shoulder the nonrecoverable costs and uncertainty of shared savings. As with most of the PCPCC data, the interest is in cost savings, much of which is passed on to primary care physicians in the cost of achieving $\mathrm{PCMH}$ status. Our experience with CPCI confirms the CPCI data that larger organizations and hospitals may benefit from cost savings, but there is little gain in small practices. We question the value of the surrogate measures of quality used for family medicine. Once a patient leaves our office we have no control over specialty or hospital costs or quality, such as hospital readmissions.

Our CPCI data shows our pretest benchmark data for hospitalization, ED visits, and readmission cost was low compared to the average of all groups in Colorado and nationally. We currently lack sufficient data from the private payers to make any judgement ${ }_{i}$ in fact 1 payer has provided no data for the last 2.5 
years. For example, our Medicare hospital admissions per 1,000 members was 140 vs 196 for the region. Our ED visits per 1,000 members were 269 vs 463 for the region. Based on our 2013-2014 data we have shown no improvement; not surprising since we were already "performing at a high level of cost savings." Costs that occur once a patient is in the ED, hospital, or cardiology office are not in our control. Also, there is little room for improvement. Ninety eight percent of ED visits were appropriate for time, place, or diagnosis. Onehalf of the increase in Medicare hospitalizations were due to elective joint replacements; any change would be rationing. The other half of the increased costs were for appropriate hospitalizations for acute myocardial infarctions or stroke; none were for out-of-control diabetes or congestive heart failure. We fell out of compliance with our 1 hospital readmission in 6 months.

First, we believe that the question is not whether small practices are missing out on the new methods of reimbursement, but whether the reimbursement models are correct. PCPCC data does not conclusively show an improvement in the Triple Aim by a movement to $\mathrm{PCMH}$, and we may be driving already high-quality small practices to consolidate. Until we have definitive proof that these surrogate measures of quality from many and competing entities (many of whom are seeking to control cost over quality) actually do what they say, we should resist the idea that PCMH will improve practice. In our small practice, this has not been the case, and the costs will not be reimbursed to us for doing all the quality work. The unintended consequence of using poorly conceived surrogate measures may be that more individual practices are forced into larger institutions. Second, family medicine and other primary care organizations need to be drivers of correct quality measures that make sense. Lastly, it appears to us that a return to transparency and a free market model (for all medical care) such as direct primary care (DPC) is a better solution for small practices than joining larger groups or participating in externally driven quality programs. In DPC, the consumer judges quality and cost directly and will reward or punish the provider of care in a timely manner.

\section{Reference}

1. Institute of Medicine. Crossing the Quality Chasm: A New Health System for the 21st Century. Washington DC: National Academy Press; 2001.

2. Liaw WR, Jetty A, Petterson S, Peterson LE, Bazemore A. Solo and small practices: a vital, diverse part of primary care. Ann Fam Med. 2016;14(1):8-15.

\title{
EDITORIAL
}

\section{The Paradox of Size: How Small, Independent Practices Can Thrive in Value-Based Care}

\author{
Farzad Mostashari, MD \\ Aledade, Inc, Bethesda, Maryland \\ Ann Fam Med 2016;14:5-7. doi: 10.1370/afm.1899.
}

$\mathrm{A}$ s Liaw et al report in this month's issue of Annals of Family Medicine, solo and small practices are under pressure from market forces propelling

Conflict of interest: Dr Mostashari is CEO of Aledade, Inc, a for-profit, startup company that partners with independent, primary care pbysicians to create and run accountable care organizations (ACOs), and enter into value-based contract arrangements with payers.

\section{CORRESPONDING AUTHOR}

Farzad Mostashari, MD

Aledade, Inc.

7315 Wisconsin Avenue, Suite 1000E

Bethesda, MD 20814

Farzad@aledade.com practice consolidation. ${ }^{1}$ However, more than one-half of all family medicine physicians - and one-half of recent graduates-are still caring for patients in practices with 5 or fewer providers. What does the future hold for these primary care physicians, especially in a world of value-based health care?

The arguments for consolidation are well known: ease of coordinated care, less duplication of tests and treatment, and decreased costs due in part to economies of scale. Under a consolidation philosophy, provider organizations evolve from solo physician practices; to groups and multispecialty practices; and finally, to fully integrated delivery systems that employ the physicians, own the hospitals, and use a 